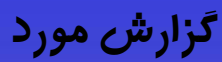

\section{كزارش يك مورد آملوبلاستوماى محيطى در خلف ماكزيلا}

حامد حسين كاظمى'، طاهره ملانيا'، حميد عباس زاده "، صفورا سيفى'، شقايق زاهد بإشاء"

'استاديار بيمارى هاى دهان و فكى و صورت دانشخاه علوم يزشكى بابل، دانشكده دندانيزشكى، بابل، ايران

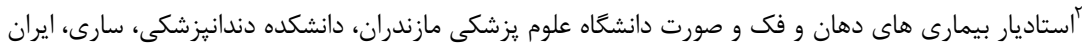

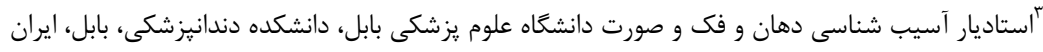

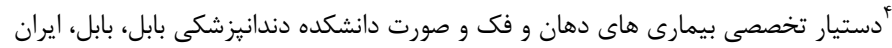

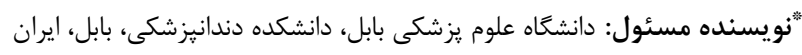

يست الكترونيك: Shaqa.zahed@yahoo.com

حكبـ

آملوبلاستوماى محيطى همتاى نادر خارج استخوانى آملوبلاستوماى مركزى /ست كه در بافت نرم اتفاق مى افتد

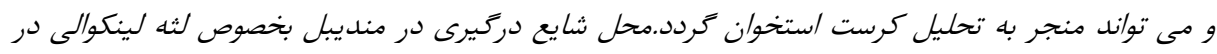

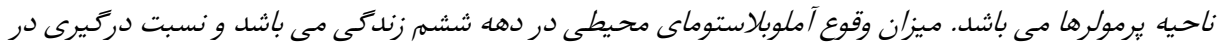

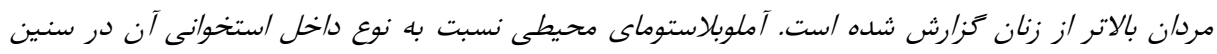

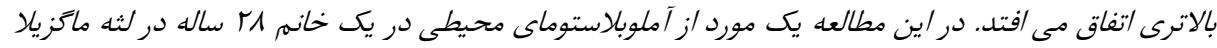
أكزارش مى كنيم. وازه هاى كليدى: آملوبلاستوماى محيطى، ضايعه لثه ایى، تومور ادنتوزنيك

$9 ه / 1 / 1 V:$ وصول

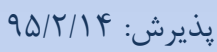




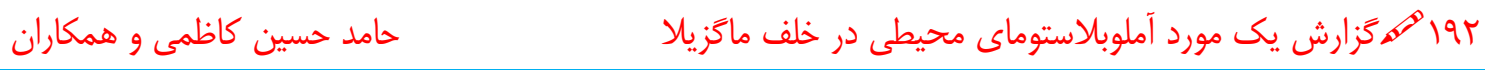

هيستوزنز PA هنوز مورد بحث مى باشد اما يك تئورى مقلمها

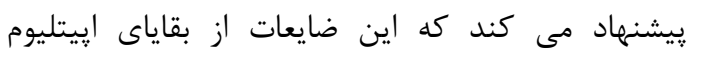

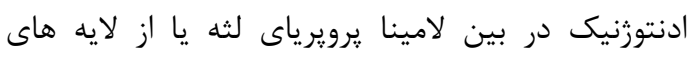

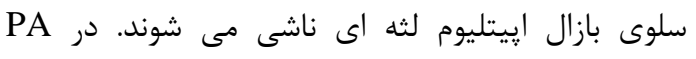

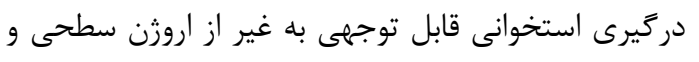

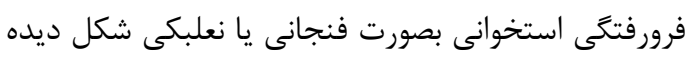

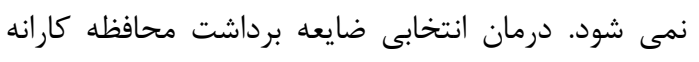

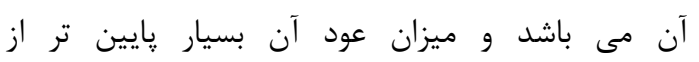

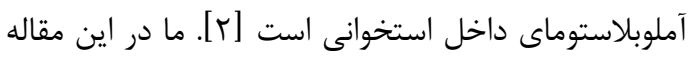

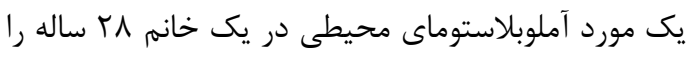

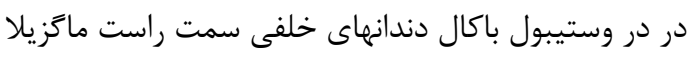
كزارش مى كنيم.

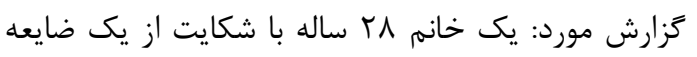

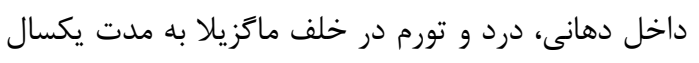

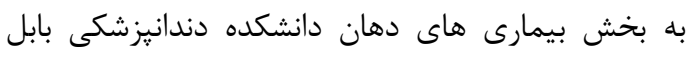

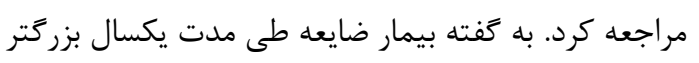

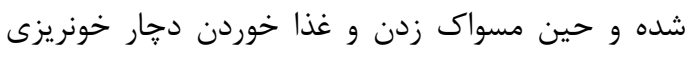

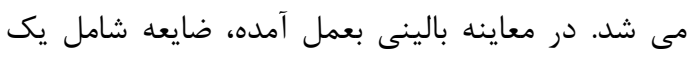

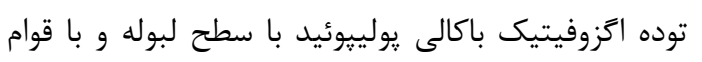

بر اساس طبقه بندى هيستولوزيك از نئويلاسم هاى

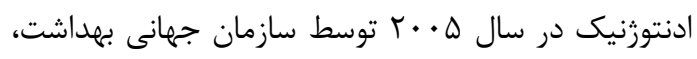

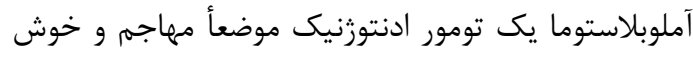

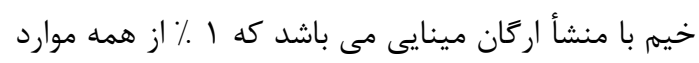

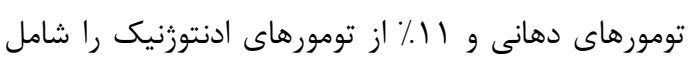

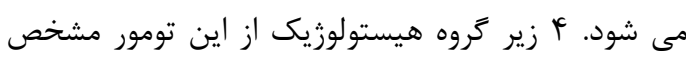

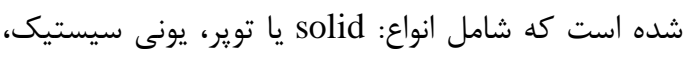

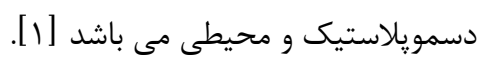

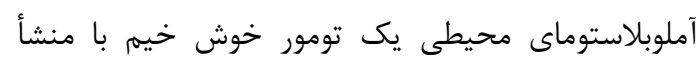

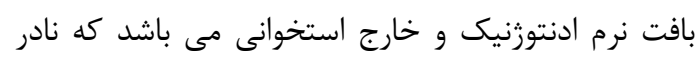

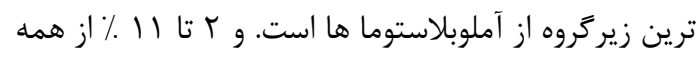

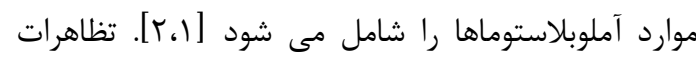

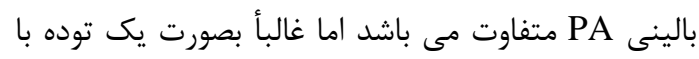

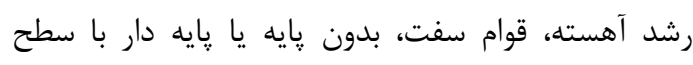

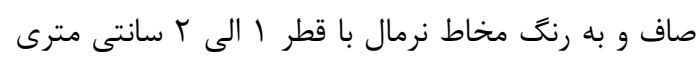

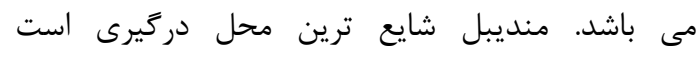

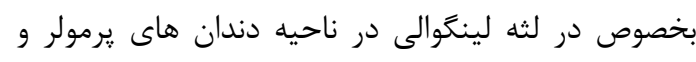

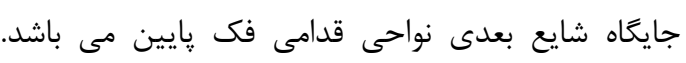

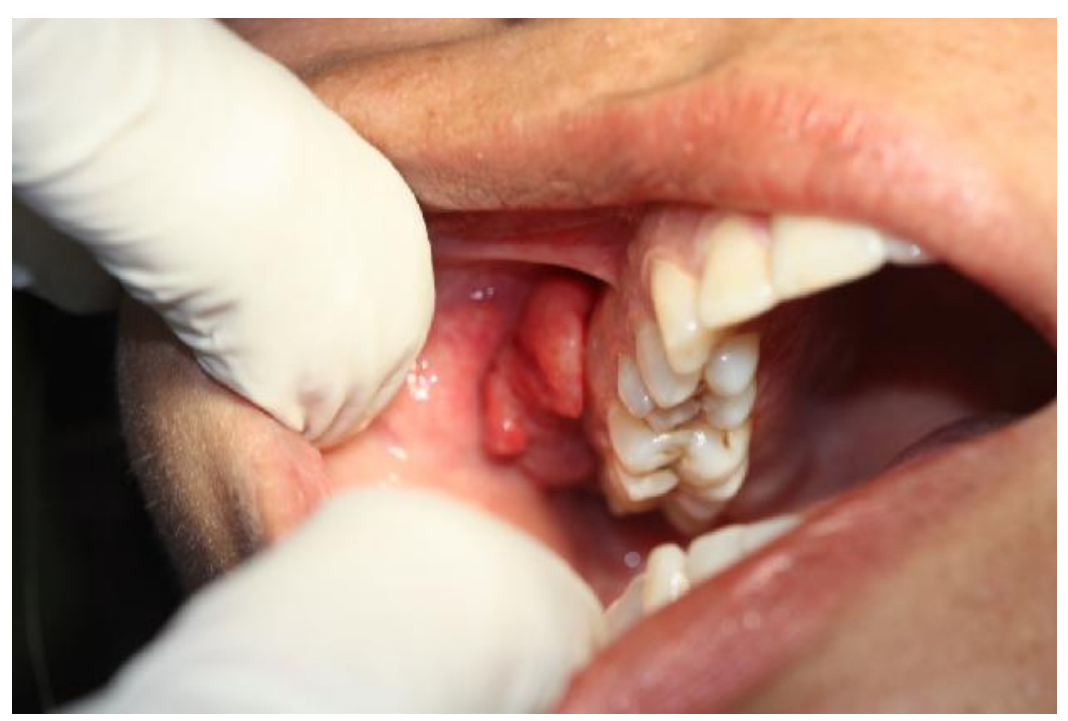

تصوير ا: نماى بالينى ضايعه 


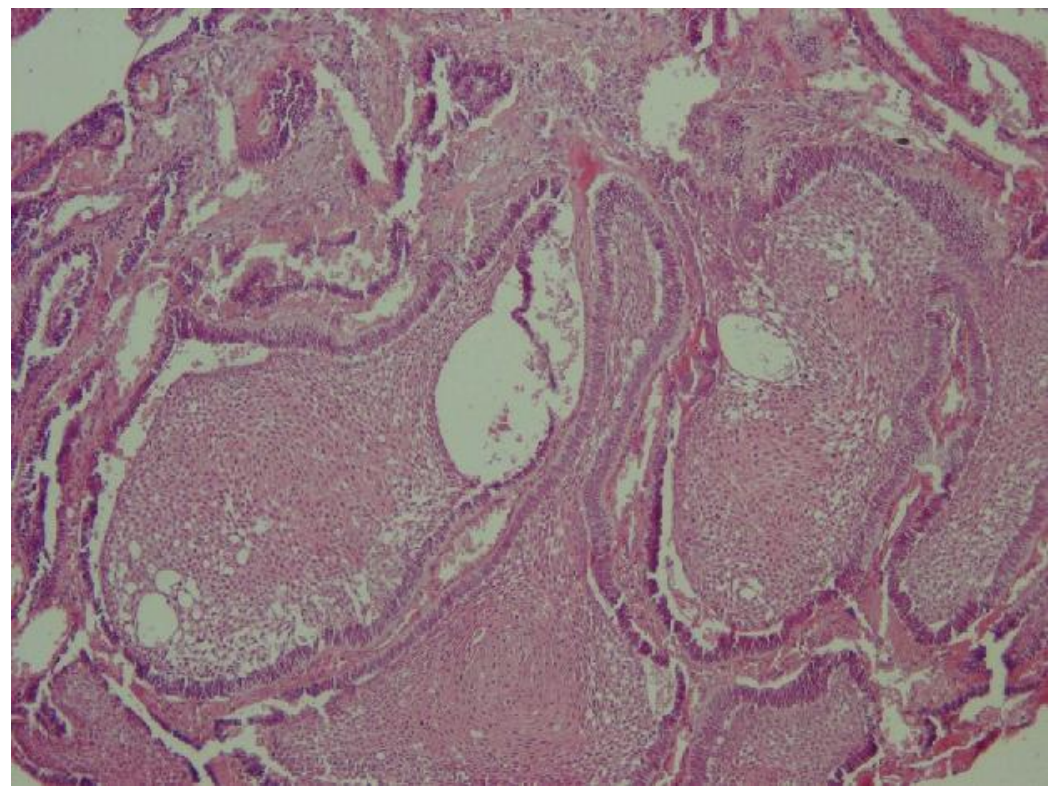

تصوير ז: نماى ميكروسكويى از بيويسى انسيرنال ضايعه، رنگ آميزى هموتو كسينين-ائوزين (100× )

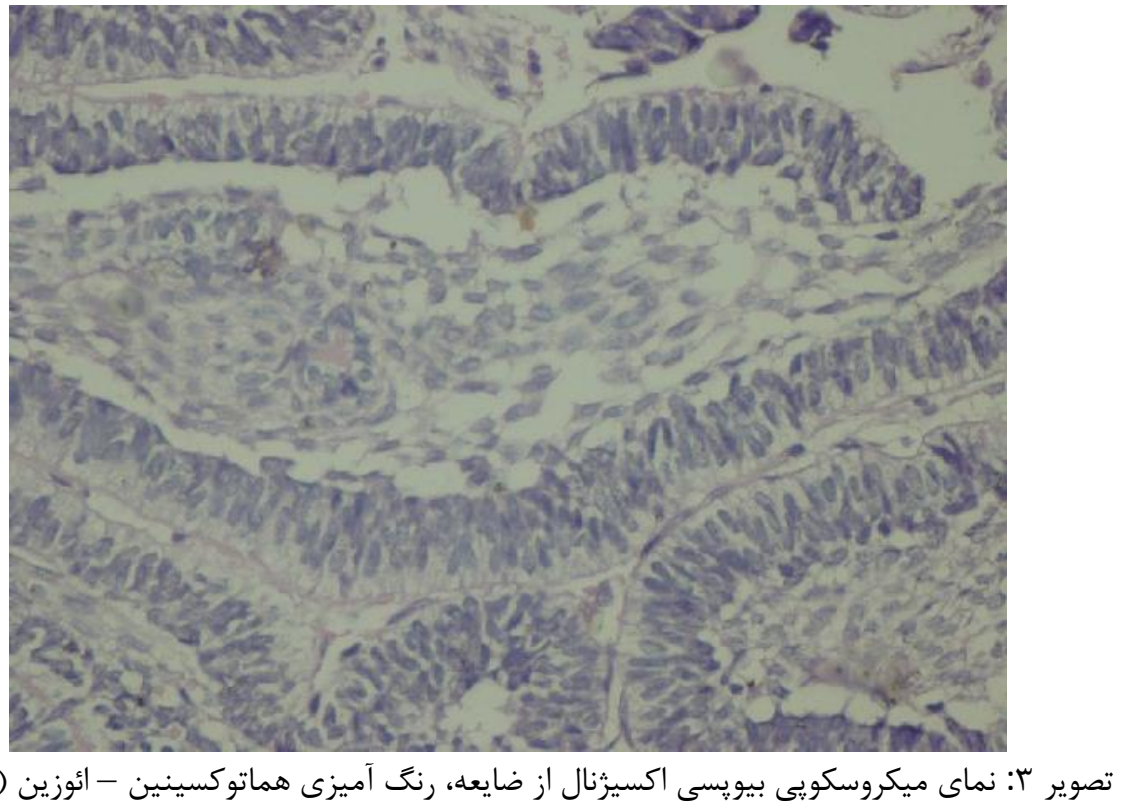

تصوير با: نماى ميكروسكويى بيويسى اكسيرنال از ضايعه، رنگ آميزى هماتوكسينين - ائوزين (400× ) 
M/F 1.14:1 استخوانى در سنين بالاترى اتفاق مى افتد ( 35

[r] ( years

منديبل شايعترين ناحيه دركيرى است بخصوص لثه

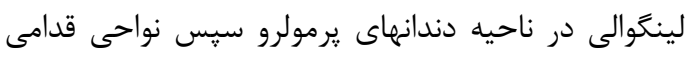

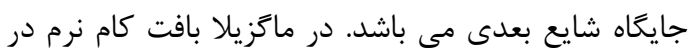

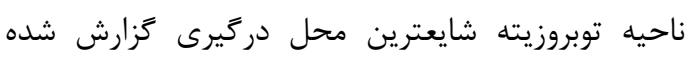

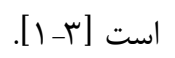

تظاهرات ماكروسكوِيك PA شامل توده اخزوفيتيك سفت

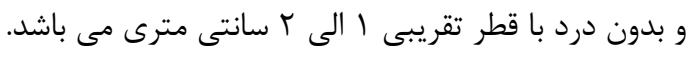
سطح تومور نسبتأ صاف بوده اما سطح كرانولر و و سنكَريزه

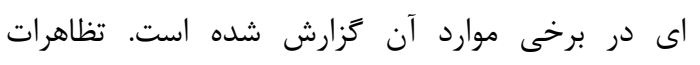

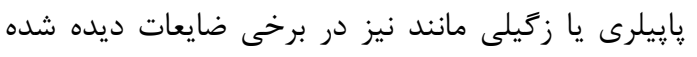

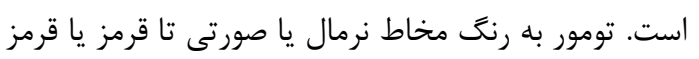

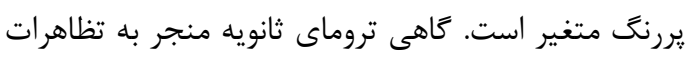
كراتوتيك در سطح ضايعه مى شود [ه، ؟].

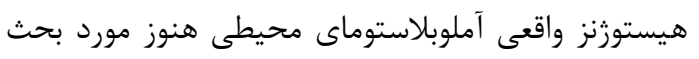

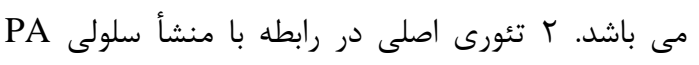

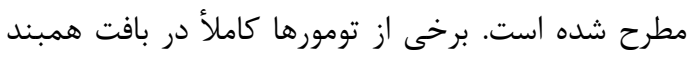

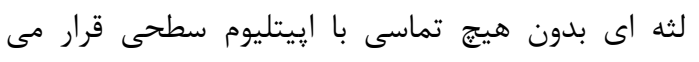

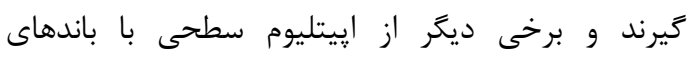

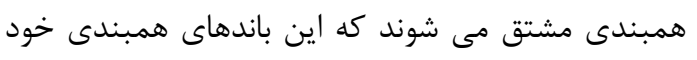

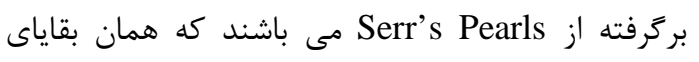

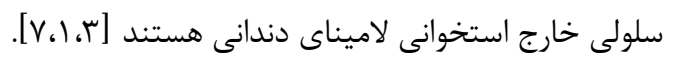

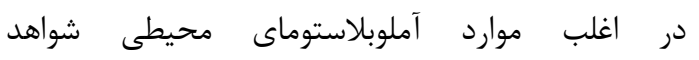

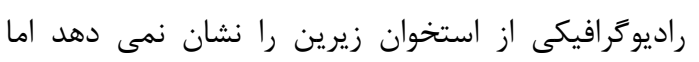

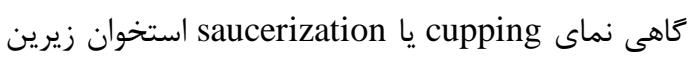

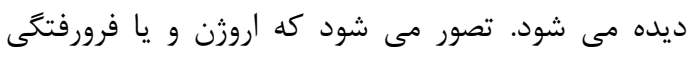

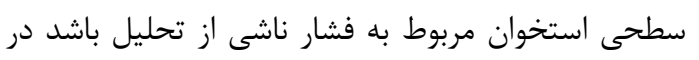

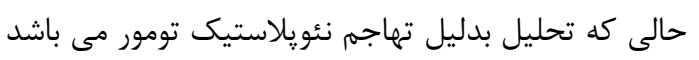

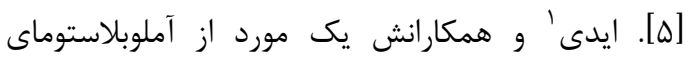

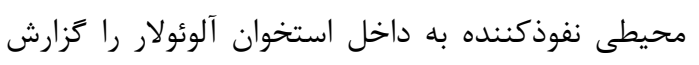

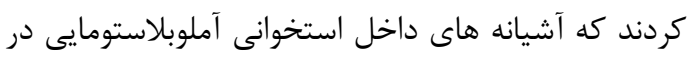

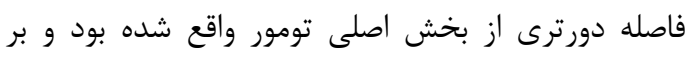

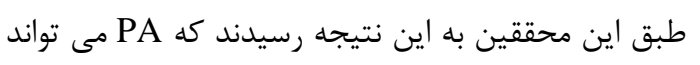
همانند آملوبلاستوماى داخل استخوانى رفتار كرده و منجر به يرفوراسيون استخوان كورتيكال شود [ع].
سفت به قطر تقريبى ץ سانتى متر بود كه از خلف دندان

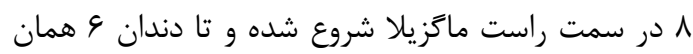

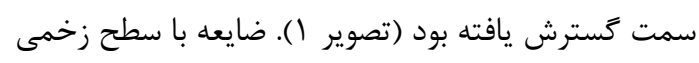

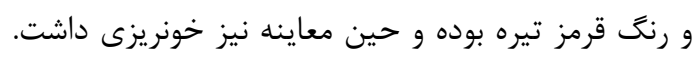

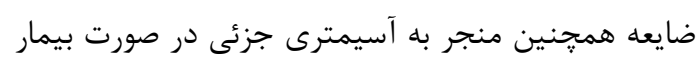
شده بود و حين لمس دردناك نبوده است.

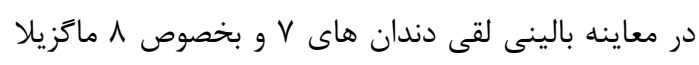

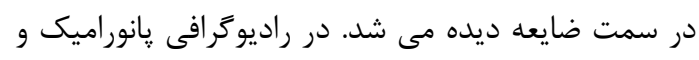

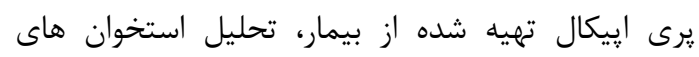

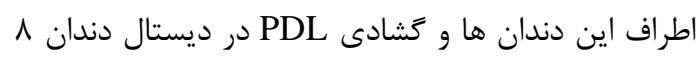

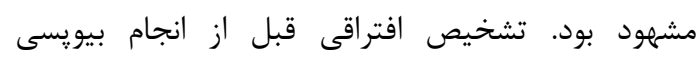
POF و PG ، PGCG بعمل آمده، ضايعه شامل جزاير با سلول هاى محيطى بلى برد

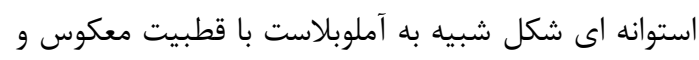

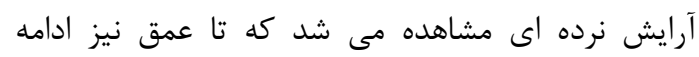

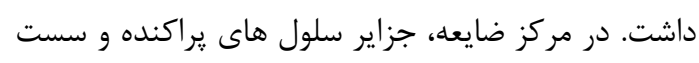

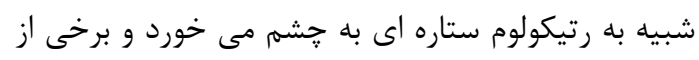

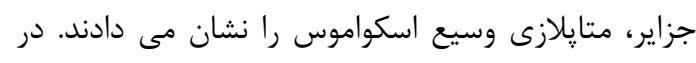

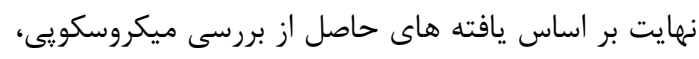

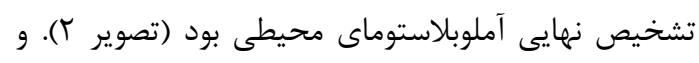

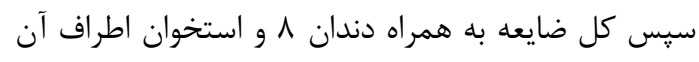

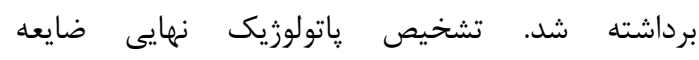

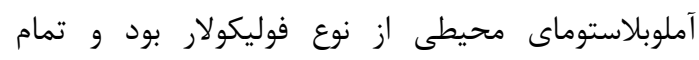
مارجين هاى اطراف ضايعه عارى از تومور بود ( تصوير گام).

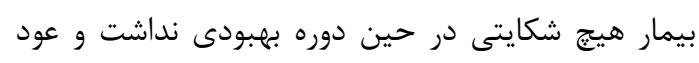

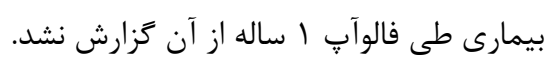

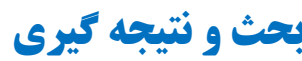

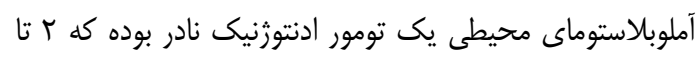

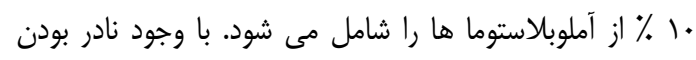

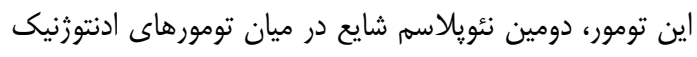

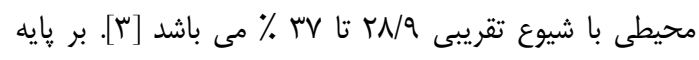

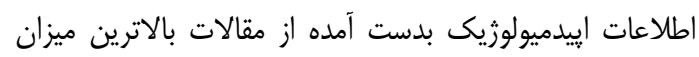

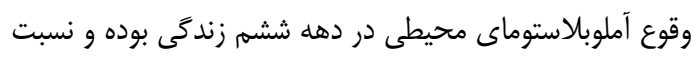

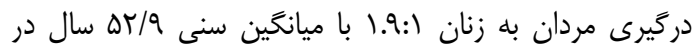

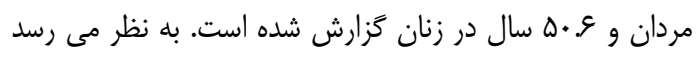

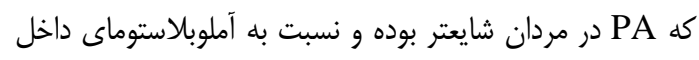


كه منشأ ضايعه از بقاياى إيتليوم ادنتوزنيك بوده و از لايه

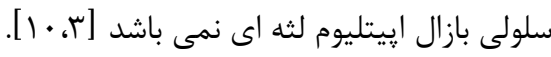

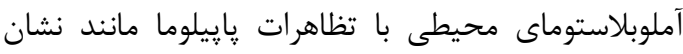

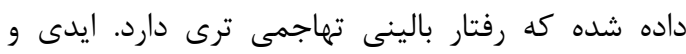

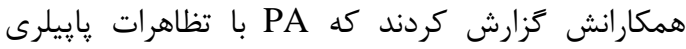
بزركتر از r سانتى مترى هستند و و با اروزن استخوان

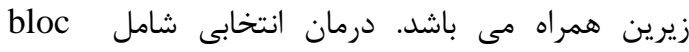

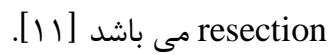
درمان انتخابى PA شامل برداشت فوق يريوستى محافظه كارانه با حاشيه كافى و عارى از تومور مى باشد. عود تومور

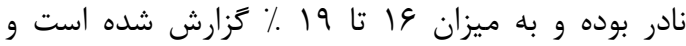
مشخص نمى باشد كه آيا عود به دليل تظاهر واقعى ضايعه

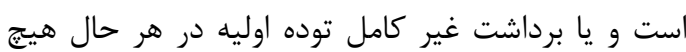
برداشت وسيع راديكالى از ضايعه توصيه نمى شود. برخى

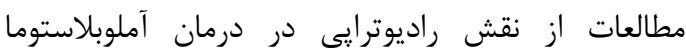

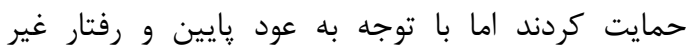
تهاجمى آملوبلاستوماى محيطى، ضرورتى براى انجام اين إنى إنائ روش درمانى وجود ندارد [ [ I]].
تظاهرات بالينى PA ياتوكنومونيك نمى باشد. در واقع آملوبلاستوماى محيطى بندرت قبل از عمل و بصورت اوليه تشخيص داده مى شود. تشخيص افتراقى بالينى تومور

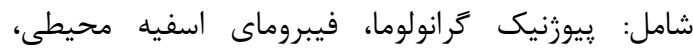
كرانولوماى زانت سل محيطى، پإِيلوما، فيبروما، واكنش به به دنجرهايى با تطابق بد همانند إيوليس فيشوراتوم و وانت هاييريلازى التهابى كام و ساير تورم هاى هايير يلاستيك محيطى مى باشد. ساير تومورهاى ادنتوزنيك كه مى تواند در تشخيص افتراقى با احتمال نادرترى قرار گيرد شامل: تومور ادنتوزنيك سنكفرشى، فيبروماى ادنتوزنيك، تومور

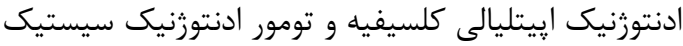

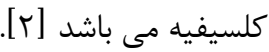
از لحاظ ميكروسكويى PA شامل إيتليوم ادنتوزنيك در إند

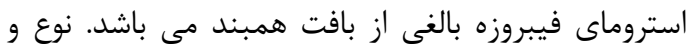

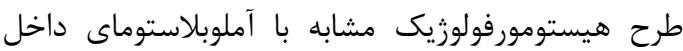

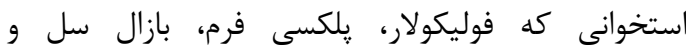
آكانتوماتوز ناميده مى شود، در آملوبلاستوماى محيطى نيز

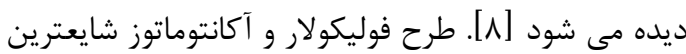

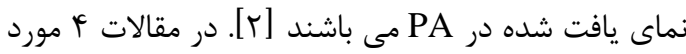
از آملوبلاستوماى دسمويلاستيك محيطى كزرش شده شده

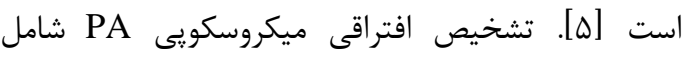

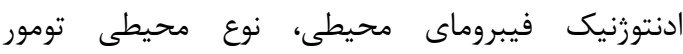
ادنتوزنيك سنگفرشى و هامارتوماى إيتليالى لثه إى إنى ادنتوزنيك مى باشد [9].

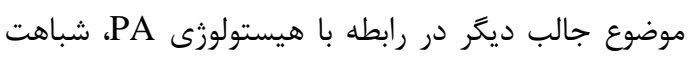

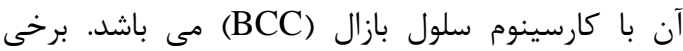

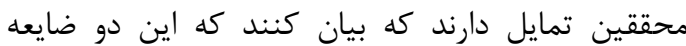
ماهيت يكسانى دارند و در برخى از جنبه ها همانند تكثير

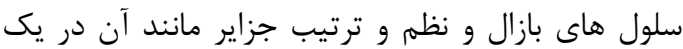
استروماى فيبروزه يكسان هستند. اما رنغ آنَ آميزى

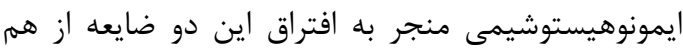

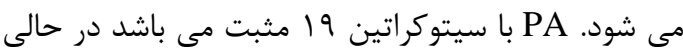

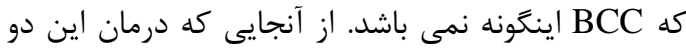

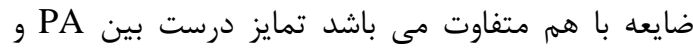
BCC

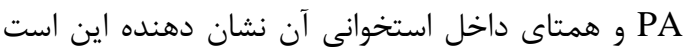




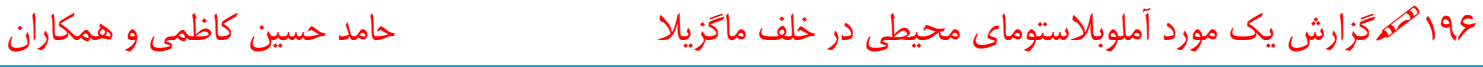

References

1. Philipsen HP, Reichart PA, Nikai H, Takata T, Kudo Y, Peripheral ameloblastoma: biological profile based on 160 cases from the literature, Oral Oncol. 2001;37:17-27

2. Nonaka CF, de Oliveira PT, de Medeiros AM, de Souza LB, FreitasRde A, Peripheral ameloblastoma in the maxillary gingiva: a case report, N Y State Dent J. 2013;79:37-40

3. Kishino M, Murakami S, Yuki M, Iida S, Ogawa Y, Kogo M, Aimmunohistochemical study of the peripheral ameloblastoma, Oral Dis. 2007;13:575-80.

4. Buchner A, Merrell PW, Carpenter WM, Relative frequency of peripheral odontogenic tumors: a study of 45 new cases and comparison with studies from the literature, J Oral Pathol Med. 2006;35:385-91.

5. Bertosis D,FaveroV,AlbanesM,and, "et al",Peripheralameloblastoma of upper gingiva: report of a case andliterature,JClinExp Dent.2014;6(2):180-184

6. Ide F, Peripheral ameloblastoma of the buccal mucosa,Oral Surg Oral Med Oral Pathol Oral RadiolEndod.2010;109:653-4.

7. Vanoven BJ, Parker NP, Petruzzelli GJ. Peripheral ameloblastoma of the maxilla: a case report and literature review, Am J Otolaryngol.2008;29:357-60.

8. Tsuneki M, Maruyama S, Yamazaki M, Cheng J, Saku T, Podoplanin expression profiles characteristic of odontogenic tumor-specific tissue architectures, Pathol Res Pract.2012;208:140-6

9. PhilipsenHP,RelchartPA,NikalH,TakataT,KndoY,Peripheralameloblastoma : biological profile based on 160 from the literature, oral oncol 2001;37(1):17-27

10. Vanoven BJ, Parker NP, Petruzzelli GJ, Peripheral ameloblastoma of the maxilla: a case report and literature review, Am J Otolaryngol.2008;29:357-60

11.Kaneko Y,UenoS.Peripheralameloblastoma a resembling a papilloma: report of case, J Oral Maxilloface Surg 1986;44(9):737-9

12.Baden E, Doyle JL, Petriella V. Malignant transformation of peripheral ameloblastoma, Oral Surg Oral Med Oral Pathol 1993;75:214-9. 


\title{
Peripheral Ameloblastoma in the maxillary gingiva: A case repot
}

\author{
Hosseinkazemi $H^{1}$, Molania $T^{2}$, Abbaszadeh $H^{3}$,Seifi $S^{3}$, Zahedpasha $S H^{4} *$ \\ ${ }^{1}$ Assistant professor , Department of Oral Medicine, Faculty of Dentistry, Babol \\ University of Medical Sciences,Babol, Iran \\ ${ }^{2}$ Assistant professor, Department of Oral Medicine, Faculty of Dentistry, Mazandaran \\ University of Medical Sciences, Sari, Iran \\ ${ }^{3}$ Assistant professor, Department of Oral Maxillofacial pathologhy, Faculty of Dentistry \\ , Babol University of Medical Sciences,Babol, Iran \\ ${ }^{4}$ Post-graduate Student, Department of Oral Medicine, School of Dentistry,Babol \\ University of MedicalSciences, Babol, Iran \\ *Corresponding Author: Babol University of Medical Sciences,Babol, Iran \\ Emil: Shaqa.zahed@yahoo.com
}

\section{Abstract}

Peripheral Ameloblastoma (PA) is a rare extraosseous counterpart of central ameloblastoma that occures in soft tissuses and may cause bone crest resorption.the most frequent onset site is the mandibular premolar region especially the lingual gingiva. The incidence of peripheral ameloblastoma in the sixth decade of life and the prevalence have been reported in men than in women. Peripheral ameloblastoma compared to the intraosseous type later in life happens .we report a case of peripheral aneloblastoma in the maxillary gingiva in a 28-year-old woman.

Keyword:peripheralameloblastoma,gingivalleasion,odontogenic tumor 